\title{
La valoración social del despacho institucional en el primer tercio del siglo $\mathrm{XX}^{1}$
}

\author{
Social valuation of institutional office furniture \\ during the first of the $20^{\text {th }}$ century
}

\author{
María-Paz Aguiló-Alonso \\ Instituto de Historia. CCHS-CSIC. Madrid
}

\section{RESUMEN}

Documentar la labor de ebanistería en el Madrid finisecular ha permitido estudiar las condiciones sociales que en los edificios públicos implicaron el desarrollo del despacho, como elemento representativo de los distintos estadios existentes, sobre todo a nivel ministerial y cuya evolución marcará la pauta de los sistemas de amueblamiento modernos. Este estudio se realiza sobre la base documental y gráfica conservada en el Ministerio de Hacienda, sobre tres acciones coordinadas en todas las Delegaciones de Hacienda, permitiendo registrar una amplia lista de casas comerciales y talleres activos entre 1900 y 1936.

Palabras clave: Mobiliario, Talleres, Casas comerciales, Industriales, Ministerio de Hacienda, Delegaciones, Despachos, 1901-1934.

\section{SUMMARY}

The documentation of cabinetwork in Madrid at the turn-of-the-century has allowed for the study of the social conditions implied in the development of institutional office furniture in public buildings. It can been seen as representative of the different levels existing especially on the ministerial plane, the evolution of which will establish the guidelines for systems of modern furnishings. This study has been carried out using the documentary and graphic materials preserved in the Spanish Treasury Department (Ministerio de Hacienda), on three coordinated actions in the local offices of this Department, thereby allowing for the registration of a full list of commercial firms and workshops active between 1900 and 1936.

Key words: Furniture, Workshops, Commercial Firms, Industrialists, Treasury Department.

\footnotetext{
${ }^{1}$ Este trabajo se inserta en el Proyecto de Investigación "60 años de ebanistería madrileña (1868-1936)", financiado por la CAM Ref. 06/0172/2002.
} 
La finalidad del proyecto "60 años de ebanistería madrileña (1868-1936)" fue la de intentar documentar la labor de ebanistería en el Madrid del cambio de siglos, el comprender la amalgama de estilos utilizados y sus posibles fuentes gráficas y buscar la actividad desarrollada por los ebanistas cuyos nombres aparecían en las listas y anuarios de los industriales de entonces ${ }^{2}$, lo que nos llevó a investigar sus métodos de trabajo y su clientela, por lo que se procedió al vaciado de archivos institucionales conservados, intentando asimismo encontrar piezas referenciadas en un buen número de edificios institucionales, que comenzaron su actividad precisamente entre los últimos veinte años del siglo XIX y los primeros treinta del siglo XX. Las sedes centrales de los grandes bancos, ministerios, casinos, las Reales Academias, las cámaras de representantes, Congreso de los Diputados y Senado, sedes de Correos o el Círculo de Bellas Artes (Aguiló 2005), todas ellas vivieron unos momentos de intensa actividad decorativa para adecuar las nuevas necesidades que se requerían en los edificios de nueva construcción, tanto para el ingente número de empleados como para los cargos de responsabilidad rígida y jerárquicamente establecidos.

Todo ello coincidiría con el auge de las Exposiciones Universales y las Nacionales de Artes Industriales, no solo de Bellas Artes, exposiciones públicas que dieron a conocer los últimos adelantos en materia de decoración. Para la difusión de este conocimiento tuvieron un valor similar tanto las Retrospectivas de Arte Sacro a nivel nacional o las del Antiguo Mobiliario Español —esta dentro de las propuestas por la Sociedad Española de Amigos del Arte de 1912-, así como la Exposición de Arte Decorativo de 1911 en la que comenzaban a exponerse novedades en los diversos campos de las artes aplicadas y en la que ya se hacía hincapié en los nombres de los creadores.

Fue realmente a partir de 1900 cuando todas las entidades públicas comenzaron a racionalizar nuevas dependencias con mobiliario creado específicamente para ellas: despachos con distintos niveles de representatividad, salas de juntas, recibidores, escaleras, bibliotecas y salas comunes donde realizaban sus funciones los numerosos empleados que todas estas instituciones requerían. Cada ministerio y dentro de ellos cada negociado, equivalente a la Dirección General de hoy, debía obligatoriamente disponer por ejemplo de una Tesorería propia, de una Asesoría Jurídica propia, de una Intervención propia, de una Sala de Visitas para cada una de estas secciones, además de los correspondientes despachos de altos cargos, directores, subdirectores, diferentes grados de oficialías, de cuerpos medios, de secre-

\footnotetext{
${ }^{2}$ En el siglo XIX comienzan a denominarse así las empresas que suministraban todos los elementos de decoración de interiores, bien fueran fabricantes o no.
} 
tarias, de ordenanzas, etc. La demanda para amueblar todos ellos era muy alta, sobre todo cuando se cayó en la cuenta de la importancia del concepto de "representatividad" y el empaque social que un amueblamiento adecuado significaba, dignificando cualquier entidad. Las campañas para soslayar bien las necesidades básicas o las simples carencias, raramente se afrontaban de un modo continuado, sino que se iban sucediendo en periodos determinados por los previos presupuestos anuales, los cuales, al cabo de meses, generalmente años, y tras largas negociaciones, lo permitían. El método de contratación del mobiliario, también en aquellos momentos, requería la presentación de varios presupuestos ${ }^{3}$, la emisión de una factura y la inclusión de las partidas en las actas y memorias anuales.

El caso que analizamos aquí, el amueblamiento institucional del Ministerio de Hacienda y sus dependencias entre 1901 y 1934, es válido como punto de partida para la normalización del mobiliario institucional español por varios motivos:

En primer lugar, por ser el único edificio en cuyos archivos se conserva la documentación ordenada de las diferentes campañas llevadas a cabo para la renovación, para el "adecentamiento" —en el lenguaje de la época- de las diversas dependencias, tanto de su sede central como de las delegaciones provinciales, lo cual permite abarcar un abanico mayor de posibilidades y modelos.

En segundo lugar, porque esa documentación refleja puntualmente el sistema de demanda, los procedimientos utilizados, tanto la adjudicación directa, como el comienzo de los concursos, en base a los presupuestos presentados, el número de los necesarios para concursar, en aumento con el paso de los años, las razones para su adjudicación, etc. La documentación conservada se compone exclusivamente de presupuestos y facturas, muy pocas veces algún dibujo asociado o una fotografía de alguna novedad en el apartado del mobiliario referente a elementos de conservación (es decir tipos de armarios con destinos especiales), y su estudio conduce efectivamente a la posibilidad de tipificar los elementos componentes de los despachos, según las estrictas categorías de sus destinatarios, tanto en número de piezas como en clases de maderas y elementos complementarios: despachos para varias personas o unipersonales, que llegarán a clasificarse, ya en los presupuestos, por el cargo: despacho de director, de subdirector, de secretaria, de jefe de servicio, etc., muchos de los cuales implican a su vez una serie de estancias anexas también a amueblar, como salas de juntas, de visitas, etc.

\footnotetext{
3 Generalmente encontramos para los treinta primeros años del siglo, uno o a lo sumo dos. Fue más tarde cuando se exigió la presentación de un tercero.
} 
Por otra parte, este estudio al ser de ámbito nacional, permite mostrar la diversidad de opiniones y gustos en todo el territorio, ya que los encargos en la mayoría de los casos, se hacían, en principio, a los diferentes talleres o industriales locales ${ }^{4} \mathrm{y}$, por último, nos permite cuantificar la actividad real de talleres de ebanistería de lujo y su diferenciación con las firmas o casas de decoración, los industriales, en general, las cuales incluían en sus ofertas desde tapizados, revestimientos, pinturas, muebles nuevos y restauración de los existentes, lámparas, alfombras, visillos, hasta grabados decorativos, que completaban sin mayores quebraderos de cabeza la decoración total de los despachos, además de simplificar los trámites de facturación.

A este último apartado hay que añadir el que esta documentación permite sacar a la luz la actividad de un sector casi olvidado por completo, el de la ebanistería, del que apenas hay datos numéricos de la primera mitad del siglo $\mathrm{XX}^{5}$.

El estudio se ha dividido en tres espacios temporales correspondientes a tres campañas diferentes ${ }^{6}$ : la realizada de 1901 a 1905 en el edificio de la calle de Alcalá, la de 1924 a 1929 comprendiendo la renovación de las Delegaciones Provinciales de Hacienda y la de 1928 a 1934, con nuevas actuaciones sobre las diversas dependencias de la sede central en Madrid?

${ }^{4}$ Con el paso de los años y la mayor facilidad del transporte a partir de los años setenta una firma de Madrid podía ofrecer condiciones más ventajosas incluso en el amueblamiento de otras sedes provinciales.

5 Para Madrid, desde los recogidos por Madoz en el siglo XIX, los de Capella, los registros de la Contribución Industrial, los anuarios de actividades industriales como los de Bailly-Ballière, además de los puntuales ofrecidos en las revistas ilustradas, pero que precisamente no suelen recoger, salvo casos excepcionales, la decoración de edificios como las sedes ministeriales.

${ }^{6}$ Apoyándonos en la conservación de documentos agrupados en tres legajos del Archivo del Ministerio de Hacienda, actualmente en el Archivo Histórico Nacional, bajo la signatura. Fondos Contemporáneos, Ministerio de Hacienda, Legajos 6.470-2, correspondientes a los años 1901-1905 y Legajos 6468 a 6470-2, reagrupados el año 1929 - reorganización del Archivo Central.

7 Tras la utilización del edificio como sede de la Junta de Defensa, al mando del general Miaja desde noviembre de 1936 hasta marzo de 1939, se devolvió el edificio al servicio del Ministerio de Hacienda, se reordenaron las dependencias en los años 40, con una gran actuación a principios de los setenta en la que se reordenó y todo el edificio, con especial énfasis en las zonas nobles de la planta principal. Aunque la documentación sobre esta actuación no se ha exhumado, si aparece documentada gráficamente en el libro de Buades Torrent (1988). 
PRÍMERA ÉPOCA, 1900-1905

Durante estos años solamente se realizaron arreglos y compras puntuales. Las primeras tuvieron que ver con la coronación de Alfonso XIII, evento para el cual se contrató con urgencia con la Real Fábrica de Tapices la realización de diecisiete reposteros con destino a las ventanas y balcón principal del edificio y otros ventisiete para los huecos de la Intervención Central. Anteriormente se habían comprado a la misma entidad alfombras grandes para las dependencias del Tribunal Gubernativo, así como para la Tesorería General, la Subsecretaría y, ya fuera del edificio central, para la Dirección de Loterías y otras dependencias de la Casa de la Moneda.

En las nueve actuaciones documentadas sobre adquisición de mobiliario de este periodo sólo aparecen cinco ebanistas diferentes, repitiéndose varias veces las compras al industrial Vda. De Alonso ${ }^{8}$. Tras unos arreglos en 1903 acomete en 1904 el mobiliario completo de la Tesorería y las dependencias de Loterías de la Casa de la Moneda y además suministra un biombo con destino al despacho del Sr. Subsecretario. La necesidad de su compra viene detallada por el habilitado de material en el informe de 24 diciembre de 1904:

por las fuertes corrientes que vienen del pasillo y por la deficiente calefacción y porque allí se celebran las sesiones del Tribunal Gubernativo y la Junta clasificadora de las obligaciones procedentes de Ultramar, se aconseja poner un biombo que evite aquellos inconvenientes y tratándose de un salón donde constantemente han de ser recibidos Senadores y Diputados y otras personas distinguidas es indispensable que todo el mobiliario este en consonancia y guarde una debida simetría para que el decorado resulte propio del objeto a que se destina?

Entre 1904 y 1905 se reorganiza la decoración del Tribunal Gubernativo y de la Subsecretaría, para ello se presupuestan 4.000 ptas. trimestrales suministrando la misma casa muebles, cortinajes, estores. Al despacho de la Inspección General se destinaba una sillería en caoba tapizada en terciopelo de Génova con mampara a juego, mientras que para la Secretaría del Subsecretario se realizaba otra "en nogal tallada, guarnecida con maderas vistas forrada en peluches de lino compuesta de sofá, dos sillones y seis sillas estilo Luis XV". Esta es la primera vez que aparece una distinción de

\footnotetext{
${ }^{8}$ Véase Anexo.

9 Subsecretaría. Negociado Central. Año de 1904. Mobiliario. Registro de negociado M-14. Diciembre presupuesto y recibo de "un biombo de 4 hojas de 2,00 x 2,20 m de alto estilo Imperio con marco de caoba forrado en terciopelo de seda, lunas biseladas y aplicaciones de bronce para el despacho del Sr. Subsecretario". 1250 ptas.
} 
clases de madera, caoba o nogal, dependiendo del destino de los muebles. Pero, sin embargo, para el mobiliario del despacho pequeño del Ministro, la misma casa provee una sillería guarnecida a la inglesa con mesa de nogal para escritorio a la cera con piel inglesa ${ }^{10}$ y para el despacho del Subsecretario mezcla tres sillas estilo Imperio en caoba con bronces y fileteadas de metal con una mesa de nogal para escritorio a la cera con piel inglesa; y como se puede observar sin ninguna correspondencia lógica entre ellas.

El sistema de trabajo para el personal subalterno ${ }^{11}$ era diferente de los usos y costumbres que se desarrollaron posteriormente. Se trabajaba en "mesas dobles de pupitres fijos para 4 o 6 personas"12, con sillas y sillones de haya o plátano con asiento de cuero color avellana y clavos grandes dorados que aparecen citados en las compras sucesivas. Una nota a destacar es que queda explicitado que las remesas que se van adquiriendo hagan juego con las precedentes. "Había viejos pupitres con tapas ruidosas en los que había que trabajar de pie" (Barea 2007: II, 189), unos tipos de mesas actualmente relacionadas con el uso escolar y bibliotecario (Rodríguez Bernis 2006: 281).

El resto de los industriales que surten al Ministerio en estas fechas son: Mariano Abollo, Manuel Sillo, Juan Herrera y Benjamín Roig. El primero hace sillones de piel y una librería giratoria para el despacho del Subsecretario ${ }^{13}$.

Segunda ÉPOCa 1924-25. RenOVación de las Delegaciones Provinciales de HACIENDA

Refundidas en 1869 las Administraciones y Contadurías-Tesorerías en una dependencia denominada Administración Económica, esta fue modificada y confirmada en 1881 bajo el nombre de Delegaciones Provinciales de Hacienda, entidades que dan nombre jurídica y formalmente a "los diversos órganos y dependencias establecidos en cada provincia para el servicio Económico del Estado con el fin de mejorar la imagen de la Administración de la Hacienda pública de cara al contribuyente, atendiendo a la simplificación de servicios, reducción de trámites, etc." (Delegaciones 1981: 1161). Bajo la

\footnotetext{
${ }^{10}$ Presupuesto 24 de febrero/ factura 19 abril 1905, por 3605 ptas.

${ }^{11}$ Como el personal "tamponero", el de la Contaduría y el de la Deuda, por citar solamente las secciones para las que se adquiere mobiliario.

${ }^{12}$ AHP. FFCC.M.H.Leg. 6470 Expediente instruido para la adquisición de mobiliario con destino a la Subsecretaría de este Ministerio.

13 Subsecretaría. Negociado Central. Año de 1901 Mobiliario. Registro de negociado A-5- MARIANO ABOLLO, 30 -IX-30-XI: "Cuenta de los muebles que se han construido para la Subsecretaría del Ministerio de Hacienda".
} 
jefatura de un Delegado de Hacienda, se organizaron en oficinas que fueron clasificadas en 1889 en tres grupos: De $1^{\underline{a}}$ clase: Barcelona, Cádiz, Coruña, Granada, Madrid, Málaga, Sevilla y Valencia. De $2^{\text {a }}$ clase Alicante, Burgos Córdoba, Murcia, Oviedo, Toledo, Valladolid, Zaragoza perteneciendo las otras 29 a la $3^{\underline{a}}$ clase.

En 1924 un Real Decreto ${ }^{14}$ reorganizaba los servicios centrales y provinciales de Hacienda, lo que supuso la creación de la Administración de Rentas Públicas en todas las delegaciones. Las Tesorerías-Contadurías integraron a las antiguas depositarias de Hacienda y Tenedurías de libros de las Intervenciones de Hacienda. Apareció como órgano intermedio el Tribunal Económico Administrativo, albergando cada Delegación la Intervención (Fiscal y de Tributos), la Administración de Rentas Públicas, la Abogacía del Estado, la Tesorería y la Inspección, creándose además en junio de 1926 subdelegaciones en otras ciudades.

Algunas delegaciones, bien por ocupar espacios nuevos, bien al multiplicarse las secciones y por tanto las oficinas, tuvieron que ser amuebladas completamente. En otras, las más de las veces, de menor entidad, solo se contempló amueblar el despacho del delegado y como mucho su secretaría, contratándose en muchos de los casos reparaciones y retapizados de asientos. Por lo mismo los presupuestos fueron variables, en un abanico económico que oscilaba entre 1500 hasta 30.000 ptas. En la documentación recogida en el Ministerio de Hacienda ${ }^{15}$ se observa que la decisión de las adquisiciones de mobiliario estaba en manos del propio Delegado Provincial.

\section{Tipos de muebles utilizados}

La mayoría de las partidas que se contemplan en esta documentación se componen de presupuestos y facturas, y los conceptos casi siempre incluyen sillerías y mesas de despacho. Con respecto a las primeras se observa que aún no aparece el tresillo (conjunto compuesto de sofá y dos butacas), que como tal denominación comienza a utilizarse posteriormente, sino el de sillería con composición variable. Una media razonable podría ser la presupuestada por Antonio González Del Rey, de Salamanca, compuesta de un sofá, tres sillones y cuatro sillas forradas ${ }^{16}$.

Aparece también entonces la denominación mesa ministro y por estas fechas por primera vez con tapa de luna, pero no solo en las mesas de

\footnotetext{
${ }^{14} \mathrm{RD}$ de 21 junio de 1924.

${ }^{15}$ AHP. FFCC.M.H. Leg. 6381-1 y 6381-2.

${ }^{16}$ Incluida en su catálogo con el no 340 (Presupuesto 2.350 ptas. r.n.47/2121923, 3 diciembre de 1925).
} 
despacho de dimensiones regulares sino también en las grandes. Arturo Barea, en su insuperable descripción del Madrid de esos años, expresa bien el poco sentido que el seguimiento de la moda tenía:

hace menos de un mes que se cubrieron todas las mesas con lunas de cristal. Las mesas en su mayoría tienen un tablero central forrado de hule rojo o verde y un marco ancho de madera barnizada alrededor. Directamente sobre este marco pusieron las lunas y claro han quedado en hueco en el centro [...] cuando pusieron las lunas pedí una plancha de goma porque veía que la iba a romper (Barea 2007: I, 357).

\section{Inversiones comparativas en la compra de mobiliario en las diferentes Dele- gaciones de Hacienda}

Entre las inversiones mayores realizadas destaca la de la Delegación de Hacienda de Granada para la misma sede de la calle Buen Suceso, utilizada desde 1889, que se ampliaría más tarde a la calle Escudo del Carmen. Se presentaron dos presupuestos en 1925 para todas las oficinas de la delegación: de la Amuebladora Granadina (Manuel Campos) de 41.100 ptas, y el otro, que fue el aceptado, de Miguel Mavit de 20.700 ptas. La diferencia de presupuesto se explica porque este último, además de adjuntar un inventario de lo que hay viejo y de lo que hace falta, presupuesta pormenorizadamente el despacho del delegado con muebles "estilo Renacimiento" mientras que para el resto de las dependencias lo hace con sillones, sillas y percheros de madera curvada.

La Delegación de Hacienda de Almería en 1930 estaba dividida en dos sedes, una en la calle Reyes Católicos 5, que albergaba el Tribunal Económico Administrativo provincial y otra en la calle Gerona 17, en la que radicaba la Administración de Rentas Públicas, la Tesorería y la Delegación de Hacienda propiamente dicha. Igual que para la anterior se presentan dos presupuestos, uno por Ubaldo Abad Carretero del Bazar "El León" de casi 40.000 ptas., justificado por "el estado deplorable de las dependencias" y otro, el aceptado, de aproximadamente 23.000 ptas. presentado por Rogelio Ferrer $^{17}$, muy detallado en cuatro presupuestos para la Administración de Rentas, para la Tesorería, para el despacho del Delegado y para la Intervención. En Lugo también se presentan dos presupuestos de 20.000 ptas. para toda la Delegación, sita en el desamortizado convento de monjas dominicas, por los Almacenes "La Gran Bretaña" con muebles americanos y por Manuel C. Varela ${ }^{18}$.

\footnotetext{
17 Véase Anexo.

18 Véase Anexo.
} 
En el extremo opuesto, las cantidades mínimas presupuestadas oscilando entre 1000 y 3.000 ptas., comprendían no toda la Delegación, sino solamente determinadas oficinas, como el presentado por Badillo para la Abogacía del Estado de Sevilla; Para el mismo destino en Logroño es el presentado por Dionisio Navajas ${ }^{19}$, ambos en "estilo Renacimiento español" o el de Víctor Gómez de Toledo ${ }^{20}$ también ofertando sillas de nogal "estilo español antiguo", o Redondo Hermanos de San Sebastián, Hijos de H. Hervada de La Coruña ${ }^{21}$, Gregorio de Frutos de Segovia, para el Tribunal Económico Administrativo ${ }^{22}$ en 1926. Dos presupuestos presentaron también Florencio Arcos y los Almacenes "La Competidora", ambos de Ceuta, en diciembre de 1930.

En Barcelona, antes de su traslado a la Vía Layetana en 1928, la Delegación ocupaba dos inmuebles en la calle de las Corts y en la Ronda de la Universidad. Para la Tesorería Contaduría en 1925 la Casa Munné presupuestaba muebles, librerías, mesas y sillas de haya por 988 ptas. ${ }^{23}$, mientras Antonio González del Rey en Salamanca o Eladio Campe Amaya "Casa Campe" de Cádiz y Adolfo Ramírez, un presupuesto para la Oficina de Rentas Públicas $^{24}$, y González Calvo de Segovia en 1931 presupuesta una mesa para la Delegación, sita en el palacio Arias Dávila en la calle Colón n.o $4^{25}$. Tanto Burgos, como Sevilla, Lérida —esta para la Intervención y para la Oficina del Personal- y Santander ${ }^{26}$ presupuestan un máximo de de 5.000 a 11.000 ptas.

\section{Maderas utilizadas y tipos de muebles}

Es norma general que las casas proveedoras ofrezcan para estas renovaciones muebles fabricados en las maderas más abundantes y generalizadas en cada región, así en La Coruña todo se ofrece en madera de castaño, en Logroño se ofertan más resistentes, de haya y para un tablero de mesa

\footnotetext{
19 AHN FFCC MH Legajo 6381-2.

${ }^{20}$ AHN FFCC MH Legajo 6381-2, R:N: 72/300.

${ }^{21}$ Representante de varias compañias de vapores AHN FFCC MH Legajo 6381-2, RN $57 / 247$

22 AHN FFCC MH Legajo 6381-2, R:N: 68/254.

${ }^{23}$ Figura en el Registro de contribución con Tarifa 1aㅗ , clase 3, epígrafe 4 n. ${ }^{\circ} 364$ como "vendedor de muebles finos". AHN FFCC MH Legajo 6381-1, folleto17, R.N. 68/ 283/1926.

${ }^{24}$ Otras Delegaciones de Madrid.

25 (Con un dibujo) solo una mesa de haya de Hungría con tapa de "mulesquín" (hule).

${ }^{26}$ AHN FFCC MH Legajo 6381-2/1932, incluyendo dibujos para la Junta de Contrabando.
} 
de nogal del país y, mas acorde con las tendencias europeas, en Barcelona se utilizan para este fin muebles de haya y de madera curvada.

Entre todas las Delegaciones, las de Granada, Sevilla, Vitoria, Toledo, Logroño, Almería y Lugo se decantan en esta remodelación por proponer y comprar mobiliario "estilo Renacimiento español". Esencialmente se trata de mesas, alguna librería y asientos, sillas de tijera, que claramente aparecen citadas como hamugas — como en Granada- o sillones "estilo español antiguo". Solo en un caso - en Sevilla, para la Abogacía del Estado- se acepta un presupuesto de un despacho compuesto de una mesa y un sillón frailero de cuero tallado y dorado. Si bien algunas mesas se especifica que sean de nogal, o al menos que sus tableros sean de nogal "del país", existe una diferencia fundamental entre el mueble Renacimiento y este mueble "estilo Renacimiento" que se realiza en haya color nogal. También es relativamente habitual que el haya se barnice en color caoba, en cuyo caso se propone como estilo Luis XVI.

En roble "del país encerado" presenta un presupuesto A. Bonilla en Vitoria para librerías, una mesa de vestíbulo de la misma madera "Renacimiento español" o "Barroco con hierros de su estilo", junto con un banco a juego de otro que ya existía. Del mismo tipo son los encargados para San Sebastián: "varios muebles de roble cerados", una librería con la parte de arriba con puertas de cristales y una mesa con su tapa de luna y cinco cajones, junto con dos sillones ingleses. Solo la casa Munné de Barcelona y la de Pedro Martí Armengol de Lérida ofrecen "sillones de madera curvada con asiento de haya estriados", remitiendo foto recortada de su catálogo.

Si bien hasta aquí, tras consultar la documentación del Archivo de Hacienda, tendríamos que establecer las conclusiones sobre los tipos de muebles utilizados entonces para esta clase de amueblamiento "funcional", en la acepción más común de este término, es decir para despachos de una oficina provincial de uno de los departamentos ministeriales más relevantes y posiblemente más dotados económicamente de toda la Administración del Estado, se podría establecer de un modo genérico una clara diferenciación que aparece reflejada en el tratamiento decorativo de los despachos principales, para el Delegado y en los diferentes departamentos que componen todas las delegaciones, como la Administración Provincial, el Jurado de Utilidades, el Tribunal Económico, la Administración de Rentas Públicas, la Tesorería de Hacienda, la Oficina del Catastro, la Aduana (en los casos en que esta estaba establecida, como en La Coruña o en Cádiz), y el resto del amueblamiento de estas que aparece englobado en una cantidad total "para el resto de la Delegación”. 
Excepto unas pocas delegaciones distribuidas en varios edificios como Almería ${ }^{27}$, Granada ${ }^{28}$ o Barcelona ${ }^{29}$ y las varias de Madrid $^{30}$ hasta la construcción en 1929 de la oficina de la calle Montalbán, lo común es que las oficinas ocuparan edificios preexistentes, en muchos casos conventos desamortizados: el de San Francisco en Lérida, el de monjas dominicas en Lugo, el monasterio de San Vicente en Oviedo, o edificios singulares como el palacio Anaya en Salamanca o el de Arias Dávila en Segovia y son estos despachos los primeros en la Administración del Estado que aparecen descritos como conjuntos de uno u otro estilo: Renacimiento, Barroco o, a lo sumo, Luis XVI, si bien en su composición solo se nombran mesas, sillones, algún confidente, algún sofá, estanterías y en pocos casos armarios. Todavía no aparecen el antedespacho, la sala de juntas, los despachos para personal auxiliar, tanto secretarías, como otros oficiales, algo que surgirá con claras diferenciaciones años más tarde. El conocimiento de todo estos tipos de muebles debe hacerse por aproximación estilística a lo conservado en oficinas similares tanto de la administración pública como de entidades privadas, que hayan podido mantenerse desde entonces con más o menos adiciones o recompuestos, ya que estamos refiriéndonos a más de setenta años de antigüedad, con el consiguiente deterioro, incluyendo los años de la guerra civil, que supuso la destrucción total o parcial de muchos de ellos.

\section{Las oficinas de las Abogacias del Estado en las Delegaciones de Hacienda}

Hemos tenido la fortuna de poder acercarnos de un modo fidedigno al conocimiento real de una de las oficinas de más relevancia en todas las delegaciones provinciales de Hacienda como es la de los Abogados del Estado, gracias a la publicación de un libro conmemorativo del cincuenta aniversario de la creación del Cuerpo, que tuvo lugar en 1931 y que recoge el testimonio gráfico de todos sus componentes en esas fechas ${ }^{31}$. Se trata de

${ }^{27}$ El Tribunal Económico y la Administración Provincial en el edificio de la calle Reyes Católicos 5, y el resto en el de la calle Gerona 17.

${ }^{28}$ Calles Buen Suceso y Escudo del Carmen.

${ }^{29}$ Ronda de la Universidad, y calle de Cortes desde 1910, hasta su unificación en la Vía Layetana en 1928.

301900 en el edificio anteriormente propiedad de las Platerías Martínez, en 1905 en la Casa de los Cinco Gremios, en la calle de Atocha, la Dirección General de Tesoro, la Oficina de Rentas Públicas en la de Infantas, o la casa de la Moneda.

${ }^{31}$ Agradezco vivamente al archivero del Ministerio de Hacienda, Agustín Torreblanca, tanto la localización de la documentación de aquellos años, como el conocimiento de la publicación conmemorativa del cincuenta aniversario de la creación del Cuerpo de 
un registro precioso para conocer no solo los nombres, sino las características físicas de todos ellos y, lo que es más importante para nosotros, de sus despachos, pues, además de las imágenes tomadas en la celebración de aquellos actos, todos sus componentes se fotografiaron individualmente en sus lugares de trabajo habituales ${ }^{32}$.

Hay que hacer constar que los Abogados del Estado ostentaban funciones especiales no solo ante la Administración sino también ante los tribunales de justicia, siendo el Director de lo Contencioso el jefe del Cuerpo de Abogados del Estado, cuerpo con distintivos propios ${ }^{33}$, estando establecidas sus funciones, no solo en el Ministerio de Hacienda y sus correspondientes delegaciones y subdelegaciones provinciales y locales. Se establecen también asesorías jurídicas en otros departamentos ministeriales: Fomento, Instrucción Pública y Bellas Artes, Gobernación, Trabajo y Previsión, Estado, Economía, Presidencia del Consejo de Ministros, Dirección General de Comunicaciones, de Aduanas, de la Deuda y Clases Pasivas y por supuesto en la Fábrica Nacional de Moneda y Timbre, en la Dirección General del Timbre, Cerillas, Explosivos y en la Representación del Estado en el Arrendamiento de Tabacos, así como en la Delegación del Gobierno cerca de la Compañía arrendataria del Monopolio de Petróleos, Junta Superior del Catastro, Caja de Depósitos, Consejo de Administración de las Minas de Almadén y en el Patronato Nacional de Turismo.

En los despachos que aparecen fotografiados encontramos peculiaridades diversas que, más que al mobiliario, que pasaremos a describir de inmediato, afectan al tipo de convivencia que el trabajo de los Abogados del Estado conllevaba. El número de estos cargos variaba, tanto en la Administración Central como en las Delegaciones y en las Asesorías Jurídicas reseñadas, por ello encontramos desde despachos colectivos, de hasta cuatro personas, con mesas iguales y armarios comunes, hasta los unipersonales - los menos - destinados a los altos cargos. La mayoría de ellos reflejan una funcionalidad rayana en la austeridad, cuando no en un absoluto desinterés por la comodidad o el gusto por la decoración, exceptuándose casi exclusivamente el correspondiente a los más altos cargos.

La fotografía del conde de Paredes en su amplio despacho de Director General de lo Contencioso, con sus paredes enteladas, su arrimadero de

Abogados del Estado (El cuerpo de Abogados del Estado) y de toda la documentación gráfica del mismo.

${ }^{32}$ En algunos casos las fotografías fueron retocadas en la fecha de la edición del libro, para ocultar alguna persona o para emparejar a los pertenecientes a una misma delegación u otra oficina de la Administración.

${ }^{33}$ R.O. Ministerio de Gracia y Justicia de 21 de febrero de 1906. 
madera, el retrato del creador del Cuerpo de Abogados del Estado, Juan Francisco Camacho Alcorta ${ }^{34}$, el reloj inglés de caja lacada del siglo XVIII y la gran alfombra, aparece razonablemente amueblado con su pequeña mesa de reuniones, cómodos sillones "de góndola, a la inglesa" con ruedas y tapizados en piel y su mesa "ministro" o de pedestal con tapa de luna, situada bajo el retrato de Carlos III copia del de Mengs de $1761^{35}$. Curiosamente ha sido necesaria la extensión de un cable eléctrico para lo que parece un micrófono y no ha habido problema en tenderlo, desde detrás del fichero de persiana, rodear la puerta, hacerlo descender y dirigirse sobre la madera hasta la supuesta mesa auxiliar, justo debajo de Carlos III (Fig. 1). Ante el despacho, una estrecha sala de visitas con mobiliario compuesto de dos bancos, dos sillas de brazos, dos taburetes centrando una silla de caderas,

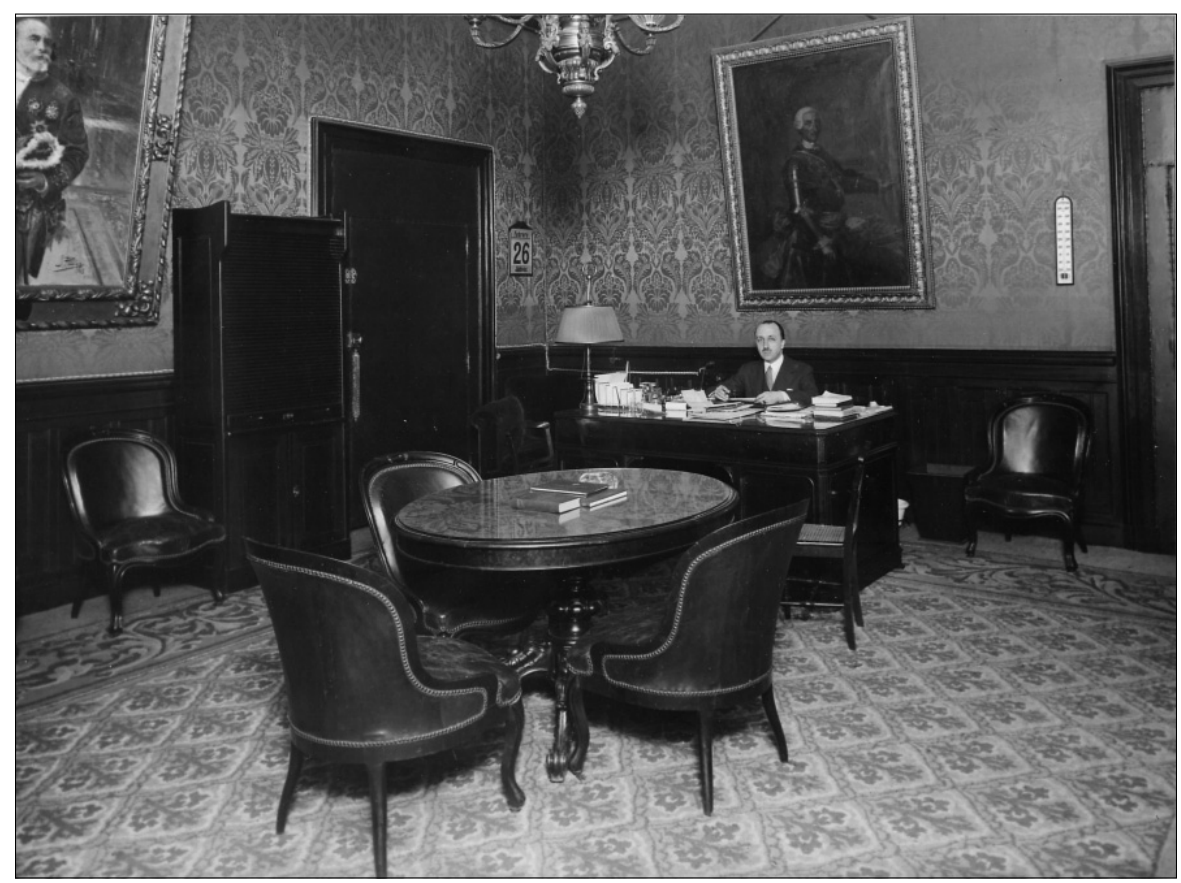

Figura 1. Despacho del Director General de lo Contencioso.

${ }^{34}$ Encargado expresamente al pintor Ignacio Pinazo Camarlench. La Hacienda Pública (1980 n.․ 609).

${ }^{35}$ Copia del realizado por Mengs en 1761 (Museo del Prado). En la información ofrecida en La Hacienda pública (1980) se afirma que este cuadro llegó al Ministerio en 1974 procedente de la Delegación de Hacienda de Madrid, pero en la fotografía de 1932 aparece ya en el despacho del Director de lo Contencioso. 
arrimada a una mesilla de fiadores de hierro, todo en el más puro "estilo español antiguo", posiblemente conservada desde la fecha de creación del cuerpo, junto con un despacho con muebles similares y sillas de estilo portugués, de respaldo alto, cueros grabados y grandes clavos de latón, que se pusieron de moda en el siglo XIX como representantes del barroco español, y una biblioteca, formada por armarios de cuatro cuerpos con puertas de cristales (Figs. 2 y 3) todo ello desaparecido durante la guerra civil.

Otra cosa eran los despachos de rango inmediatamente inferior. Los subdirectores primero y segundo ocupaban despachos estrechos y angostos, el primero con un tresillo tipo inglés tapizado con dibujos grandes a juego con las banquetas y demás elementos integrantes de la tapicería, habitual a finales del siglo XIX, como el tapete cubrechimeneas sobre la que destaca un amplio espejo, mientras que el subdirector segundo en un despacho aún más pequeño solo tiene cabida para la mesa, ya no tipo "ministro" sino de cinco cajones y que además no hace juego en absoluto con las sillas de brazos con asientos de cuero y clavazón dorada, iguales a la estantería y al estrecho armario archivador, de tres cuerpos situado tras la mesa. El del subdirector tercero, se podría ya denominar casi angosto cuchitril, con cabida justa para su mesa de haya de cinco cajones y la auxiliar para la máquina de escribir y sendas sillas de dos alturas con asiento de cuero grabado, situadas justo ante los escalones que suben a la pequeña ventana de la entonces última planta del edificio ${ }^{36}$.

Los diversos negociados de la Dirección General de lo Contencioso agrupan un amplio número de Abogados del Estado: en varios despachos aparecen hasta seis mesas, del tipo americano habitual en estos años 1920-40, todas iguales, de haya barnizada con "tapa de luna", cinco cajones con tiradores aparentes en sus frentes, pero acompañadas en cambio por sillas de brazos "tipo español antiguo" con asientos y respaldos de cuero con el escudo de la abogacía del estado grabado a un lado. Estos despachos tienen por toda decoración un reloj y un calendario, además de un elemento tan anacrónico como la escupidera (Fig. 4), pero demuestran, a pesar de su escaso interés decorativo, un deseo de unificación que se tradujo en una adquisición relativamente numerosa en la década de los veinte, mejorando un poco la desastrosa ubicación física de los letrados que componían la asesoría jurídica del Ministerio (Fig. 5).

De un modo algo diferente aparecen los despachos de los Abogados del Estado al frente de las asesorías jurídicas integradas en otros departamentos. Si en algunos casos como en la Dirección General de la Deuda y en el de Aduanas, es una adición de dos mesas diferentes entre sí, o una polvo-

\footnotetext{
${ }^{36}$ Las plantas cuarta y quinta del edificio fueron construidas entre 1940 y 1963.
} 

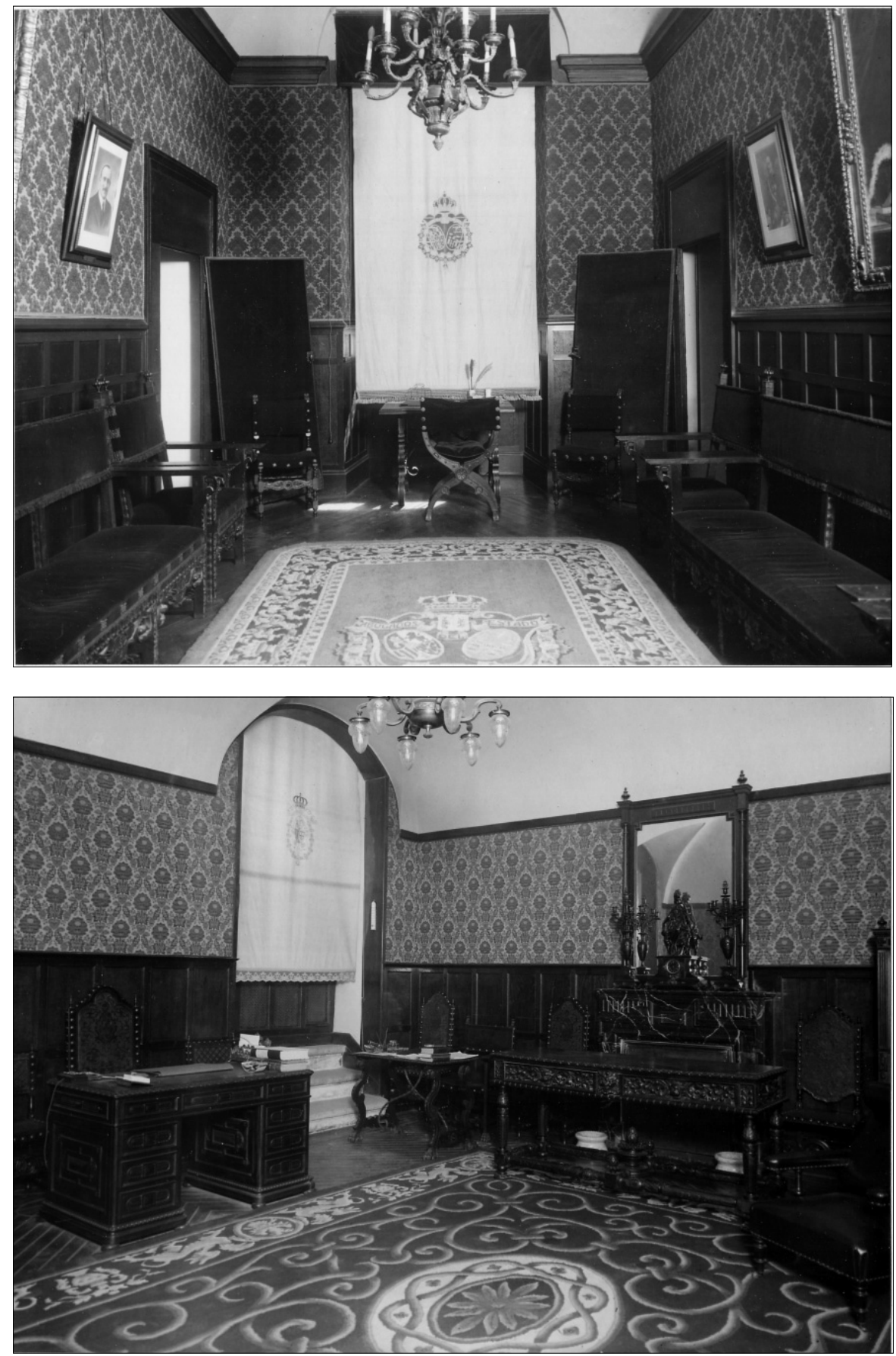

Figuras 2 y 3. Sala de visitas de la Dirección General de lo Contencioso. 


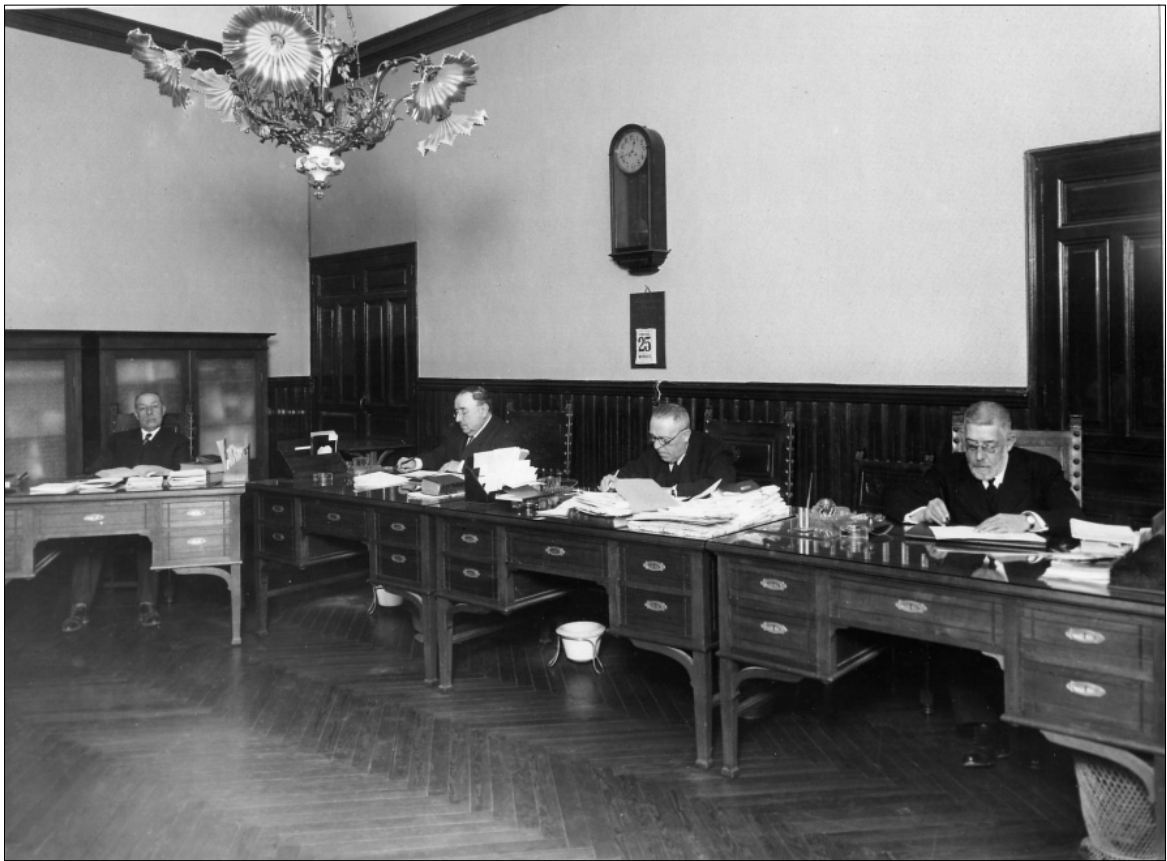

FiguRa 4. Dirección General de lo Contencioso. Negociados de Causas, Capellanías y Pleitos.

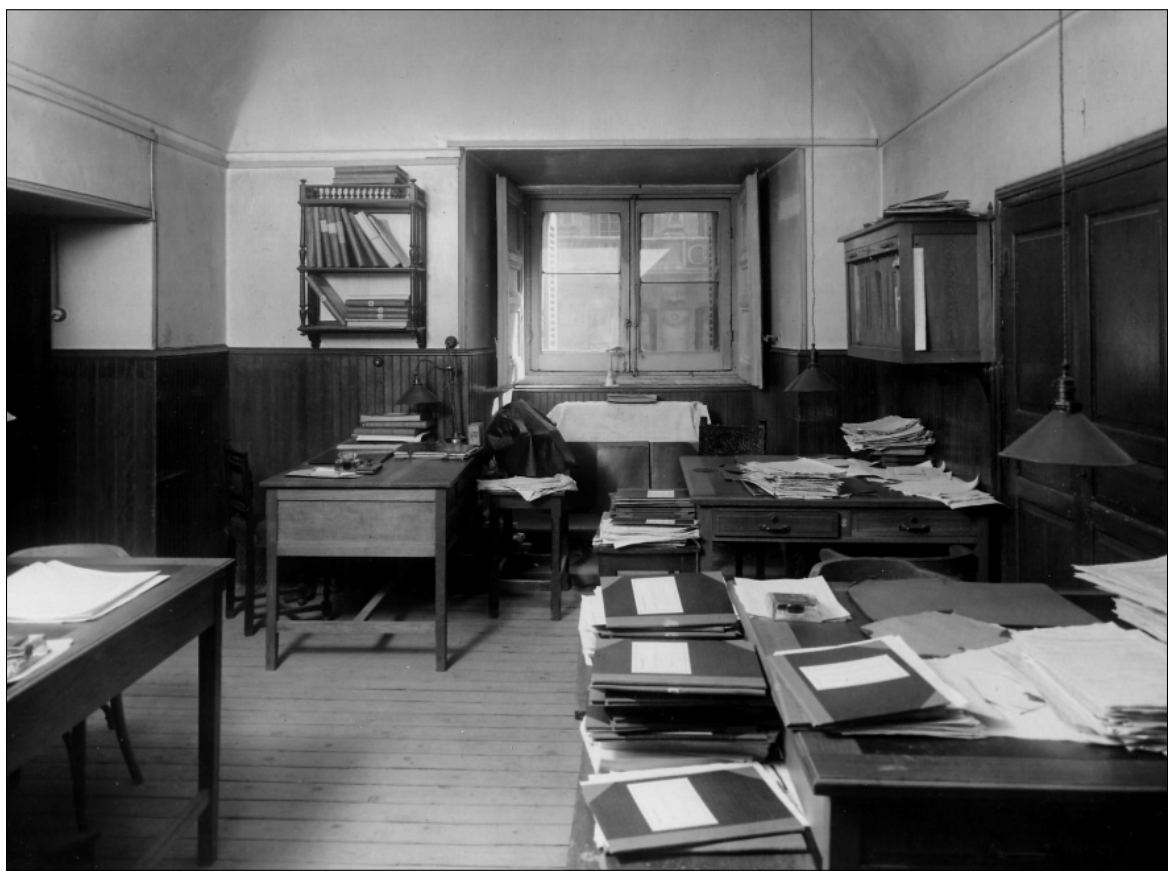

FiguRA 5. Asesoría Jurídica del Ministro. 
rienta y anticuadísima como la de la Caja de Depósitos, o estrechos despachos con pasados enseres como en la Fábrica Nacional de la Moneda (Fig. 6), tanto en el Ministerio de Fomento, en el de Instrucción Pública y Bellas Artes, en la presidencia del Consejo de Ministros o en los Tribunales de Madrid (Fig. 7) y Barcelona estaban situados en despachos razonables. Unos posiblemente heredados o construidos en "estilo Renacimiento": mesas con fiadores de hierro profusamente talladas y armarios a juego, también tallados y a veces con cristales emplomados y otros estaban amueblados a la inglesa en el más puro estilo Chippendale, como el del Ministerio de Trabajo y Previsión o el del Consejo de las Minas de Almadén (Fig. 8), también a la inglesa pero más cercano al estilo Reina Ana con sus buenas butacas chester ${ }^{37}$. En estos despachos más evolucionados de las asesorías parece que se dice

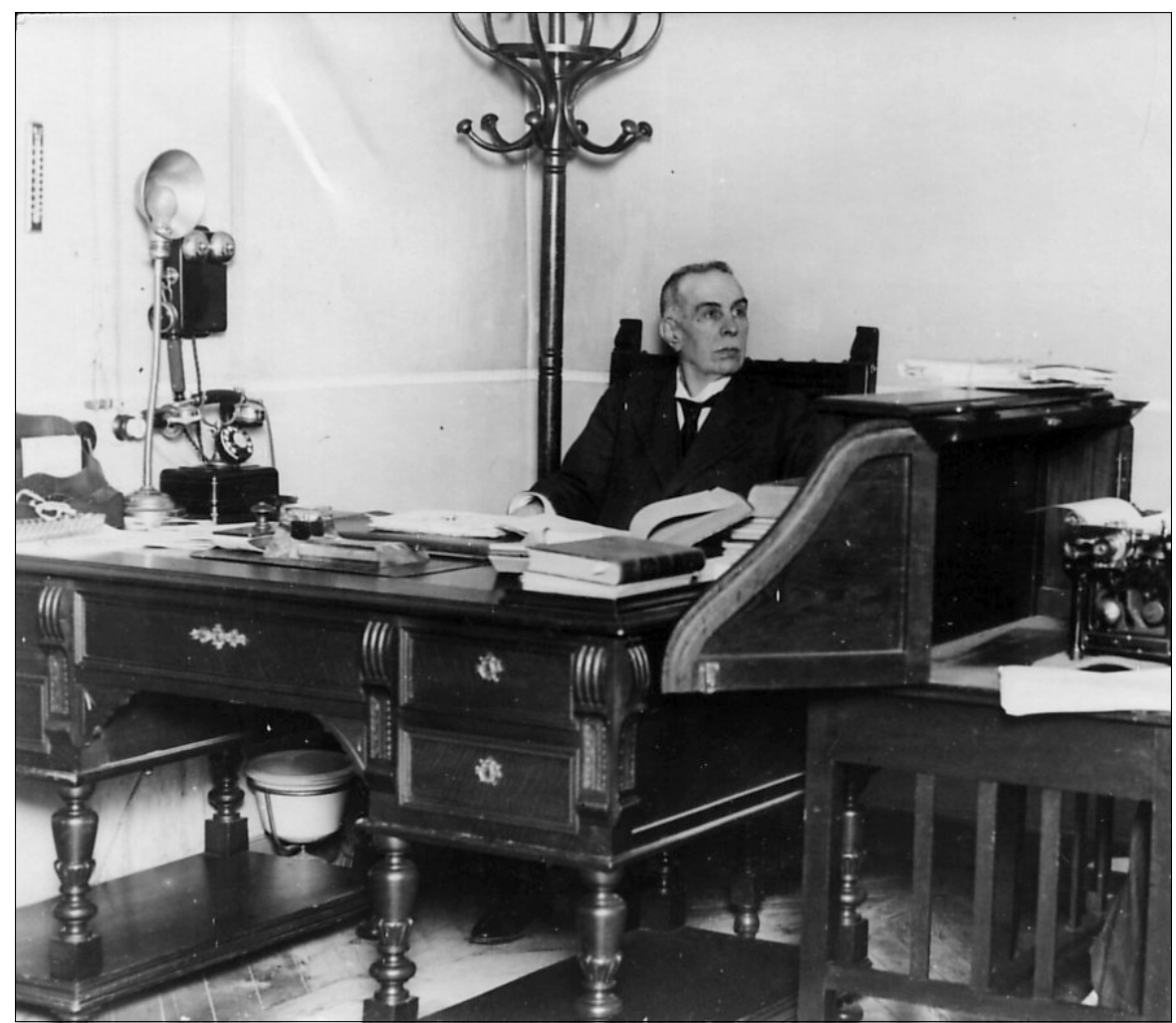

Figura 6. Asesoría Jurídica. Dirección General de la Fábrica de la Moneda y Timbre.

${ }^{37}$ Sofá Chesterfield "Tapizado en piel, capitoneado, de respaldo y brazos ligeramente exvasados. Asociado a las estancias masculinas y se considera adecuado para salas de billar, halls y bibliotecas" (Rodríguez Bernis 2006: 313). 


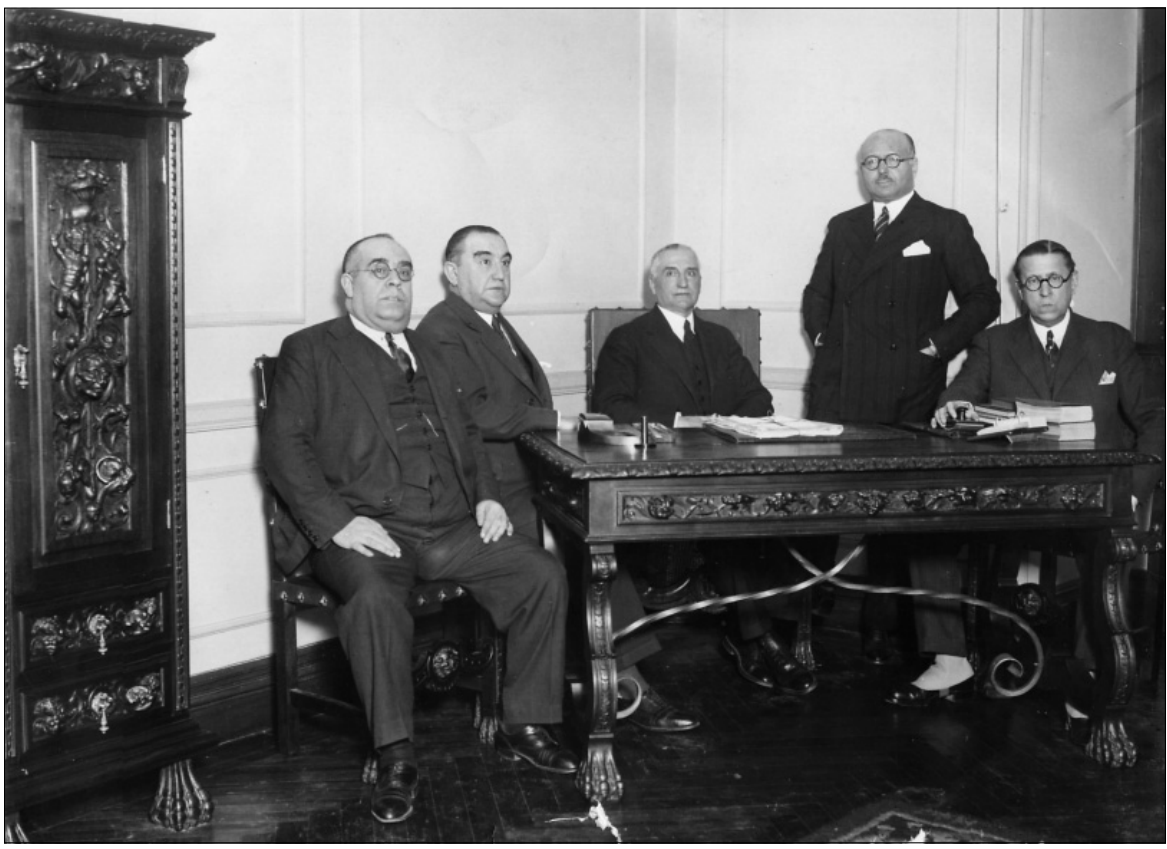

Figura 7. Abogados del Estado en los Tribunales de Madrid.

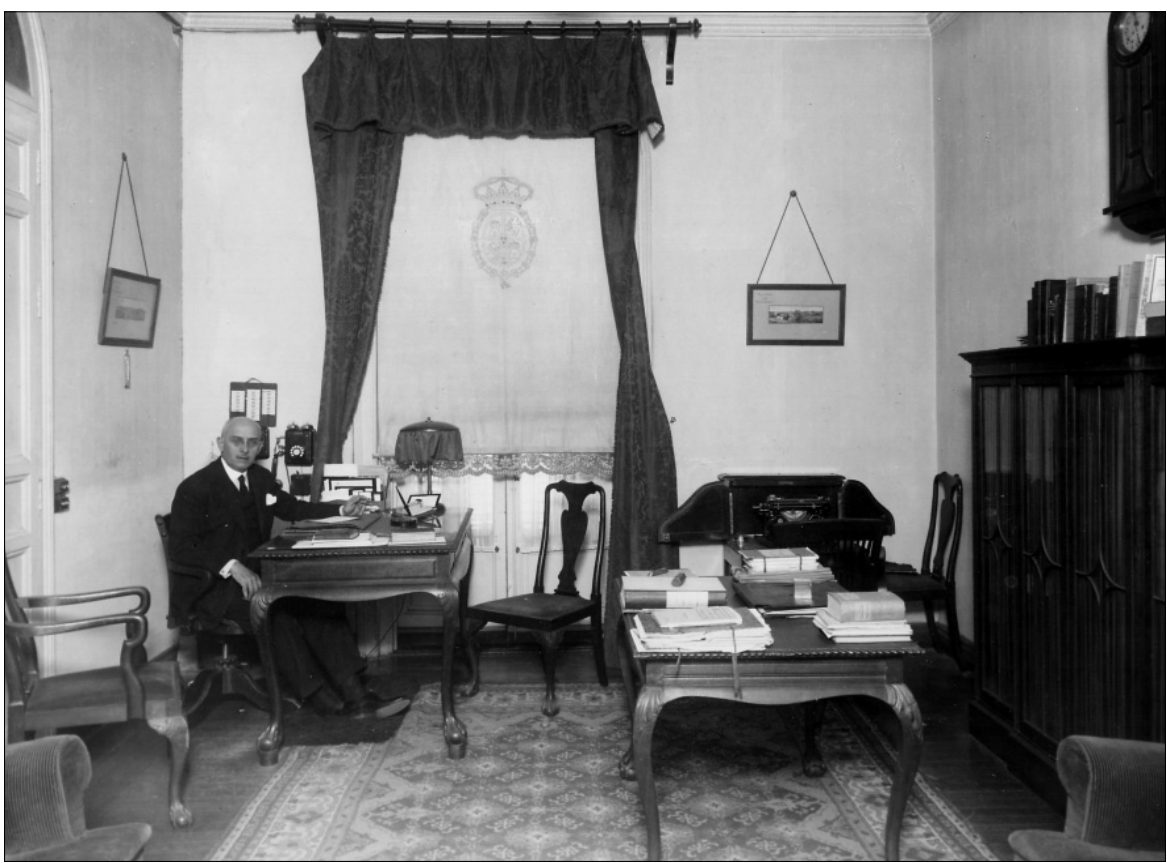

FiguRA 8. Asesoría Jurídica en el Consejo de Administración de las Minas de Almadén. 
adiós a la silla de brazos con asiento y respaldo de cuero, apareciendo ya sillones giratorios de tipo americano.

En los asientos es donde se aprecia una mayor aproximación a la búsqueda de la comodidad, comenzando a aparecer para la mesa de despacho, sillas giratorias, sillones de respaldo alto tapizados, bien en cuero o tela, y sobre todo en los complementarios: tresillos completos, sofás o simples butacas "confortables", en sustitución de los bancos tapizados arrimados a la pared, que se pueden apreciar en los despachos más antiguos.

La documentación gráfica de los Abogados del Estado también resulta ilustrativa para el conocimiento de las Delegaciones Provinciales de Hacienda. Según la documentación de archivo recogida más arriba, los amueblamientos realizados en el quinquenio 1925-30 reflejaban un apego a la tradición de lo que debería ser un despacho representativo de un delegado provincial, recogiéndose la contratación del mobiliario y demás elementos incluso para la decoración de sus viviendas oficiales. Así por ejemplo, estudiando las compras para el delegado de Granada se cita una "mesa de nogal estilo Renacimiento" y "sillones de los llamados hamugas" y se especifica que "para el resto de las dependencias se ofrecían sillones y percheros de madera curvada"38. Para la Abogacía del Estado de Sevilla el presupuesto incluye junto a la mesa, un "sillón frailero de cuero tallado y dorado" 39 . Mesas y armarios tallados estilo Renacimiento o Barroco los encontramos en los despachos de los Abogados del Estado de Gerona, Lérida, Logroño y Ávila o la silla de la subdelegación de Alcoy. Un ejemplo paradigmático de un despacho tipo "Renacimiento" podría ser el del Abogado del Estado en la Delegación de Hacienda de Madrid, en la calle Montalbán (Fig. 9), que consta de mesa, armario, bargueño y sillas de cadera a modo de confidentes, todo profusamente tallado, incluido el gran armario de cinco cuerpos con cristales emplomados y el emblema del Cuerpo de Abogados del Estado. Este tipo de armario se encuentra también en los despachos de Salamanca, si bien la mayoría son despachos sencillos, estrechos y con muebles grandes, producto de un escaso detenimiento en la decoración de los mismos, como en el caso de Murcia, o producto casi de una normalización, como en los diversos negociados de la Delegación de Hacienda de Madrid (Fig. 10). En otros casos hay un apego formalista a la tradición autóctona, como el compuesto por tipologías y tallas de tipo popular gallego en el de la subdelegación de Santiago. También pueden encontrarse despachos grandes y aparentemente destartalados con muebles pequeños, pero conservando aspectos definitorios

38 AHN FF.CC. M.H. Leg.6.381-1 Subsecretaría. Negociado Central. Año de 1925. Mobiliario Reg.Neg. 52-230.

39 Ibidem Reg.N. 50-256. 


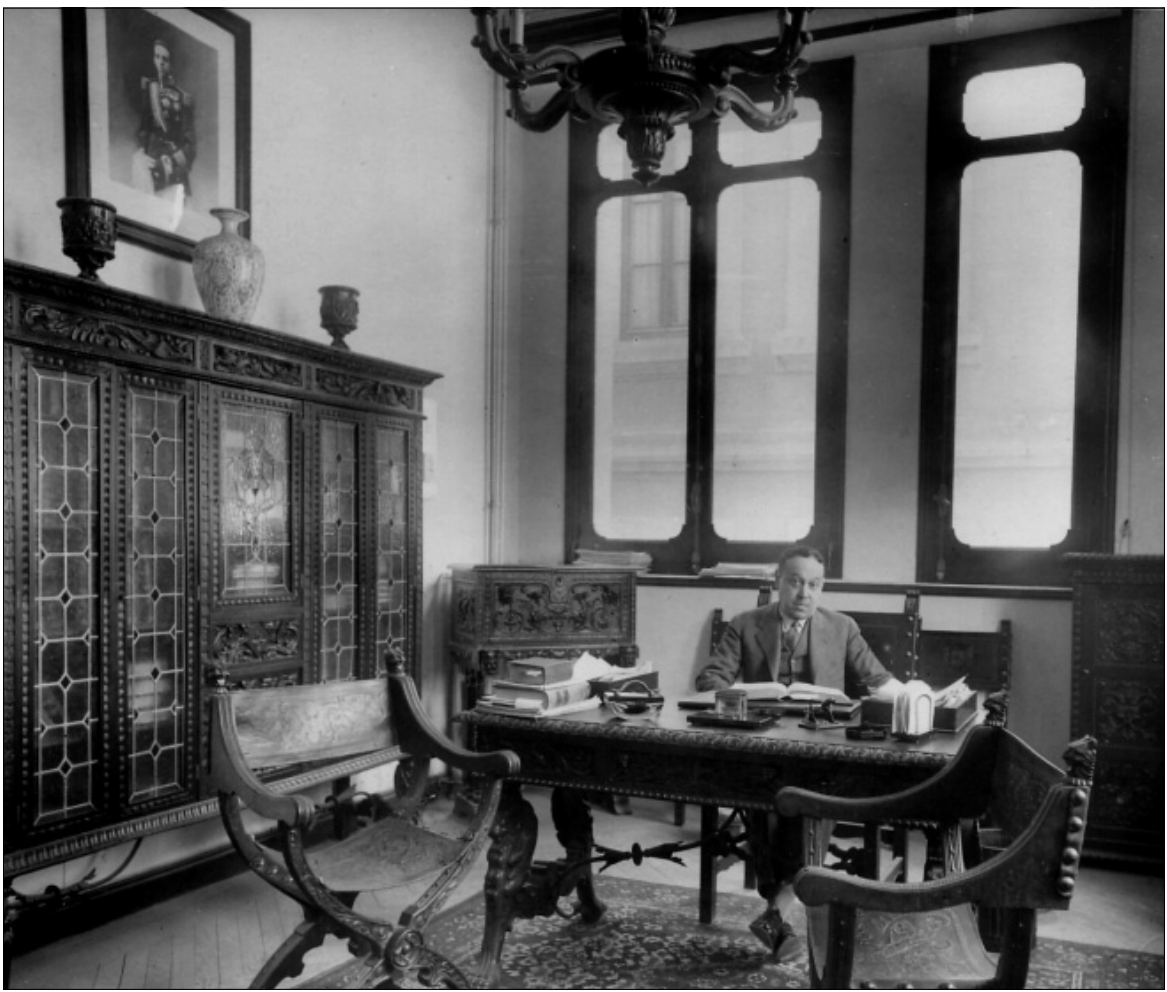

Figura 9. Abogacía del Estado de la Delegación de Hacienda de Madrid.

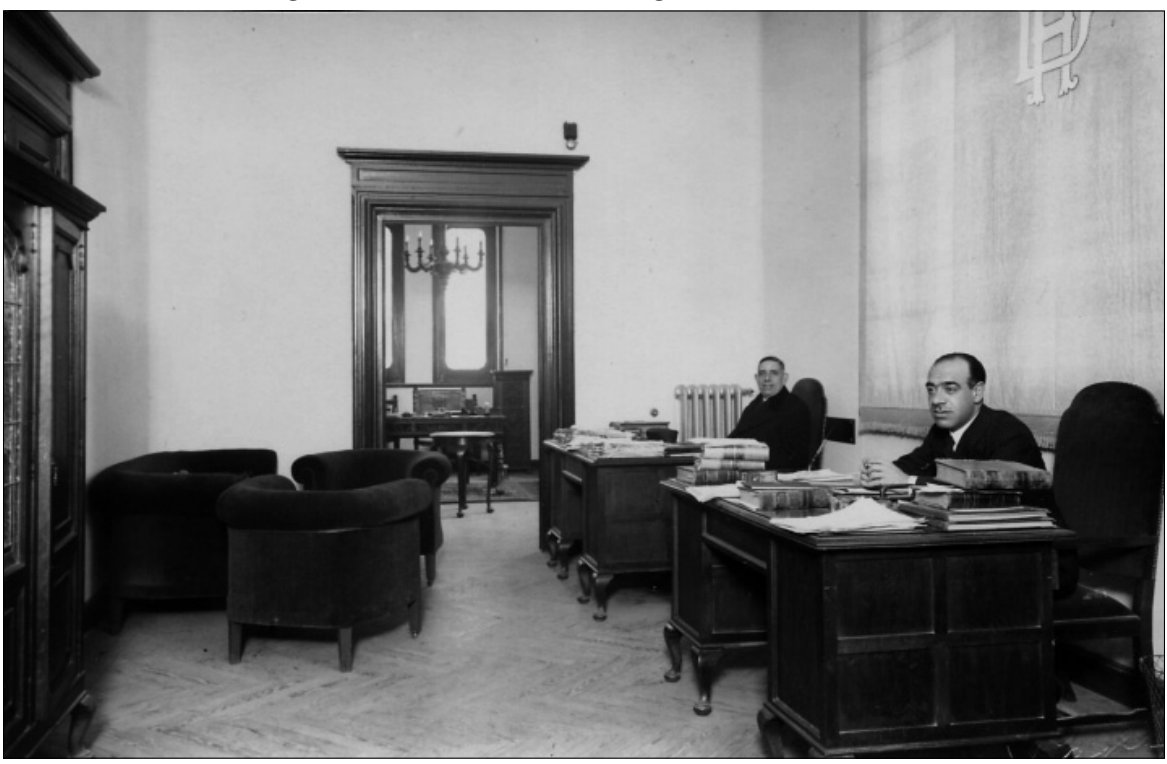

Figura 10. Delegación de Hacienda de Madrid. 
del mueble local como en Baleares. En otros casos, como en San Sebastián (Fig. 11) o Bilbao, están mas cercanos a la tradición inglesa, sobre todo en cuanto a la utilización de mesas de pedestal, tipo "ministro", sillas y sillones tipo chester, incluidos algunos elementos curiosos como silletas o banquetas altas, tapizadas en cuero capitoneados y mesillas auxiliares, también cercanas al gusto inglés.

Un número relativamente abundante de los despachos destinados a los Abogados del Estado en las delegaciones y en algunas subdelegaciones, así como en varios negociados del propio Ministerio, se amueblan con el material de oficina, denominado ya en la época "estilo americano" ${ }^{40}$, generalmente de roble, en principio solo encerado - como muchos de los que aparecen en los presupuestos y facturas para las delegaciones- y mas tarde barnizados. Son muebles muy resistentes y de líneas depuradas que han soportado muy bien el paso del tiempo, tanto física como estilísticamente.

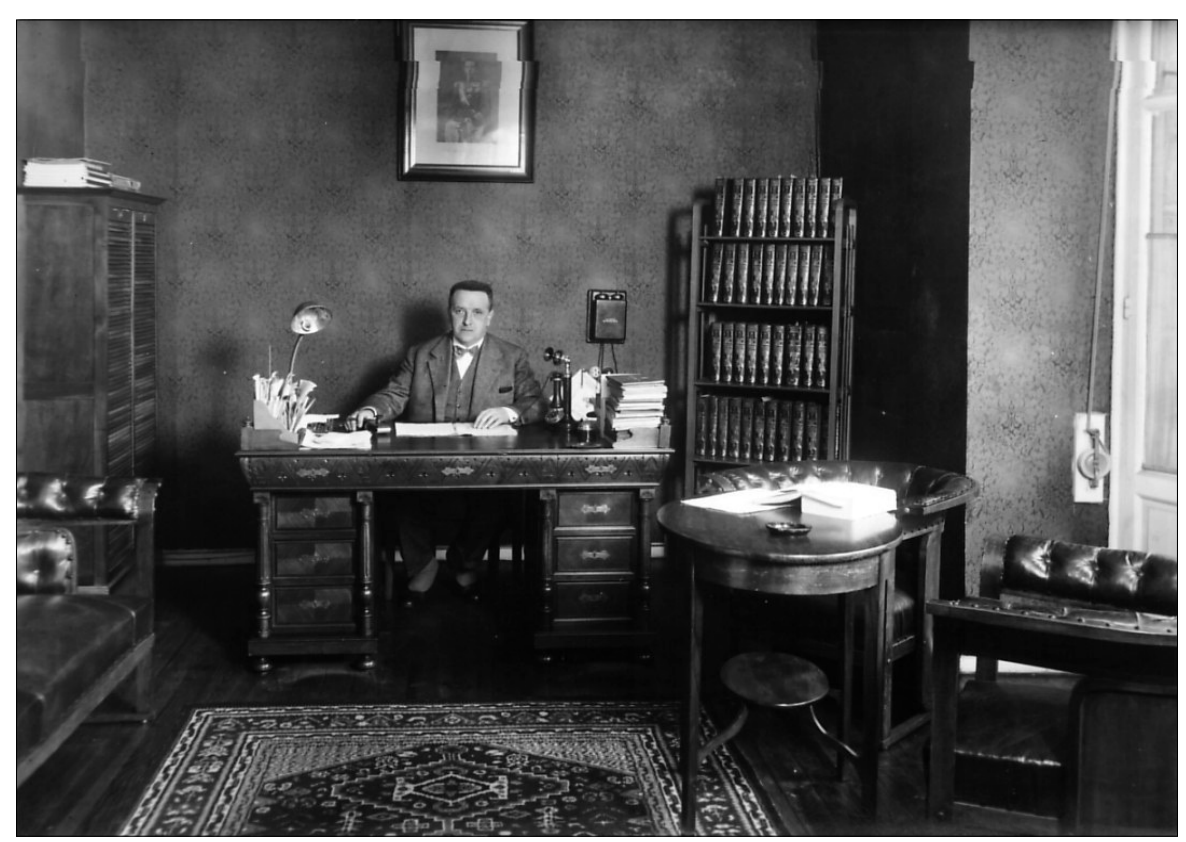

Figura 11. Abogado del Estado. Delegación de Hacienda de Guipúzcoa.

${ }^{40}$ Existían varias casas especializadas en este tipo de muebles. En Madrid destacó Luis Asín Palacios, Preciados 23, Muebles de Oficina, activa durante todo el primer tercio del siglo, conservándose interesantes ejemplares en el CCHS procedentes del Instituto de Estudios Árabes y la mayoría de los que componían el mobiliario de la antigua sede del CSIC en la calle Duque de Medinaceli 6. 
Por último, hay que destacar un cierto número de despachos en los que primó el deseo de coherencia con los tiempos: nuevos diseños, nuevas disposiciones de las estancias, que pueden servir como ejemplo de los tímidos avances de la Administración Pública en este campo.

Las novedades principales llegaron en el capítulo de los asientos. Así se conservan algunos bancos-librerías de respaldo alto, muebles puestos de moda en tiempos del Modernismo, creaciones interesantes en relación a su utilidad y estética, aunque no tanto - y esta posiblemente fue la causa de su fracaso- en lo que respecta a su movilidad y conservación, pudiendo considerarse como decoración fija. De ellos hay algunos ejemplos, el más antiguo el de la delegación de Alicante, encajado en una librería y en mal estado de conservación por lo que aparece recubierto de una tela clara, que muestra su pertenencia a un momento anterior, o el de la de Albacete (Fig. 12) donde dos mesas en forma de cajón semicircular, con sus sillones de respaldo alto, encuadran un banco también de respaldo alto tapizado y con sobrecuerpo sombrerero, siguiendo el concepto antiguo de mueble útil, claramente destinado a las visitas, pero que se ha realizado a juego con las mesas, los sillones y la banqueta, realizados todos en madera oscura y con tachones metálicos redondos en los frisos de todos sus elementos. Otro estilo, menos "elegante" pero igualmente cohesionado aparece en las fotografías del despacho que ocupó Luis Pérez y Flórez Estrada en la delegación de Álava (Fig. 13). Se trata de una habitación de altas puertas de cristales con visillos en sus dos tercios inferiores y capialzados de terciopelo con

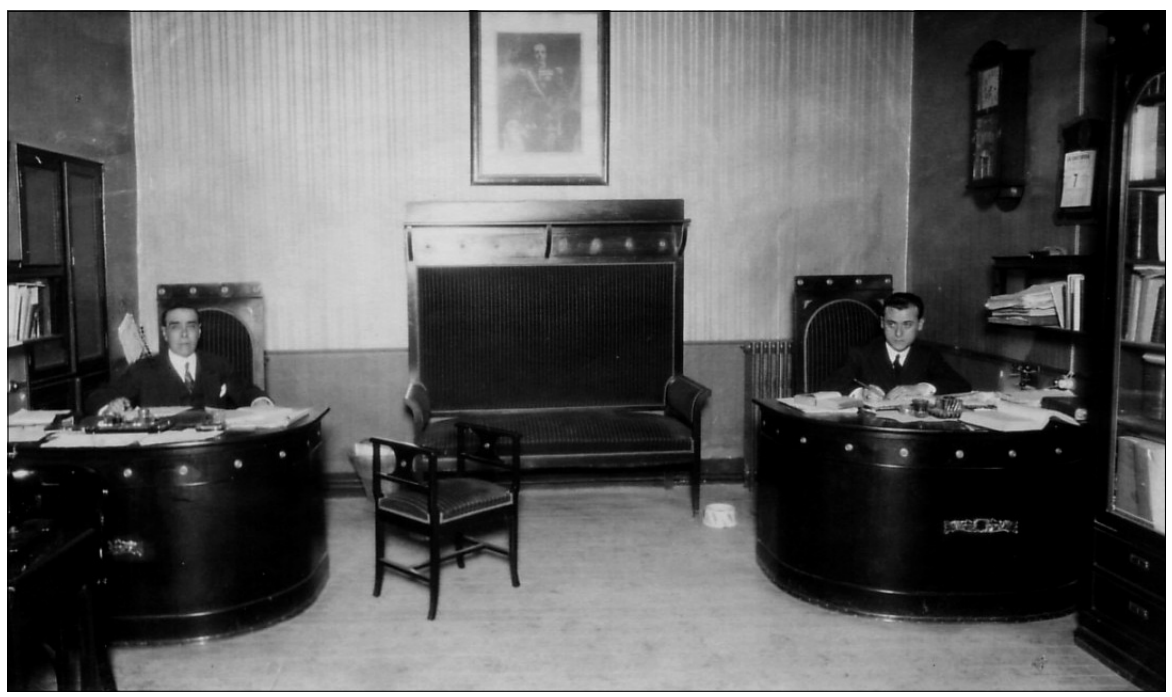

Figura 12. Abogacía del Estado en la Delegación de Hacienda de Albacete. 


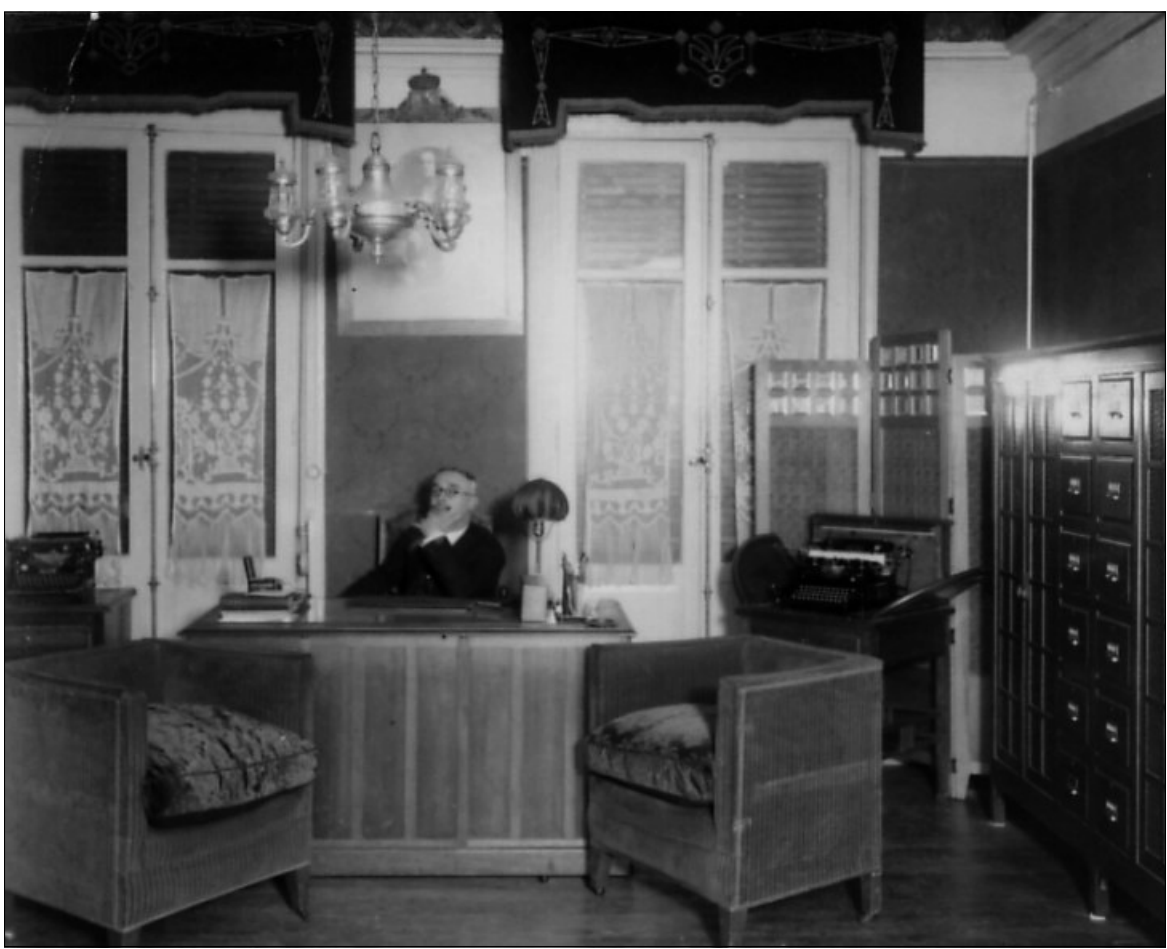

Figura 13. Abogacía del Estado en la Delegación de Hacienda de Álava.

pasamanería, entre las que se situaba una mesa grande de tipo cajón rectangular y listoneado vertical, en color claro, a juego con un biombo, muy en la línea centroeuropea de principios del siglo $\mathrm{xx}^{41}$, un armario con cuerpos de cristales a los lados y fichero de gavetillas central y como confidentes dos butacas tipo cajón con grandes almohadones delante y con las sillas, en la misma línea de madera vistas y pequeño respaldo tapizado, propias de este conjunto. En él se conserva asimismo un elemento interesante de estos despachos-oficinas: la mesa auxiliar para máquina de escribir escamoteable, situada junto al escritorio, alta y con tres alas, lo que indica que era utilizada por el propio letrado. También destaca el despacho de la Abogacía del Estado en la subdelegación de Jerez, amplio y confortable, con sillas tapizadas en cuero de aspecto directamente inglés y butacas con costados de rejilla y resto tapizado, con un mesita baja de cantos achaflanados,

${ }^{41}$ Una mesa listoneada de tipo centroeuropeo aparecen también en la Delegación de Guipúzcoa. 
situadas ante una librería corrida bajo alto friso de madera, siguiendo las tendencias eduardianas.

El mismo sistema de disposición de despacho se observa en la delegación de Santander: dos mesas amplias, con sus correspondientes ficheros verticales de persiana a los lados, encuadran un banco central con listones en el respaldo, que en este caso se ha realizado incluido en el paramento posterior de armarios y librería cubriendo la pared hasta una altura media (Fig. 14). Para la delegación de Santander se conserva un presupuesto con dibujos y planos presentado por Manuel Restegui ${ }^{42}$ en el que se incluye un interesante escritorio clasificador victorero, fabricado por "Victorero y hermanos. Lastres. Asturias".

TERCERA ÉPOCA. Ministerio DE HaCIENDA, 1927-1934

Paralelamente a la labor emprendida en las delegaciones de Hacienda, la sede central del Ministerio cree oportuno remodelar y rejuvenecer sus secciones más tradicionales, haciendo especial hincapié en la planta noble del edificio de la calle de Alcalá, sobre todo en lo referente a la carpintería fija de los espacios cercanos a los despachos del Ministro y Subsecretario.

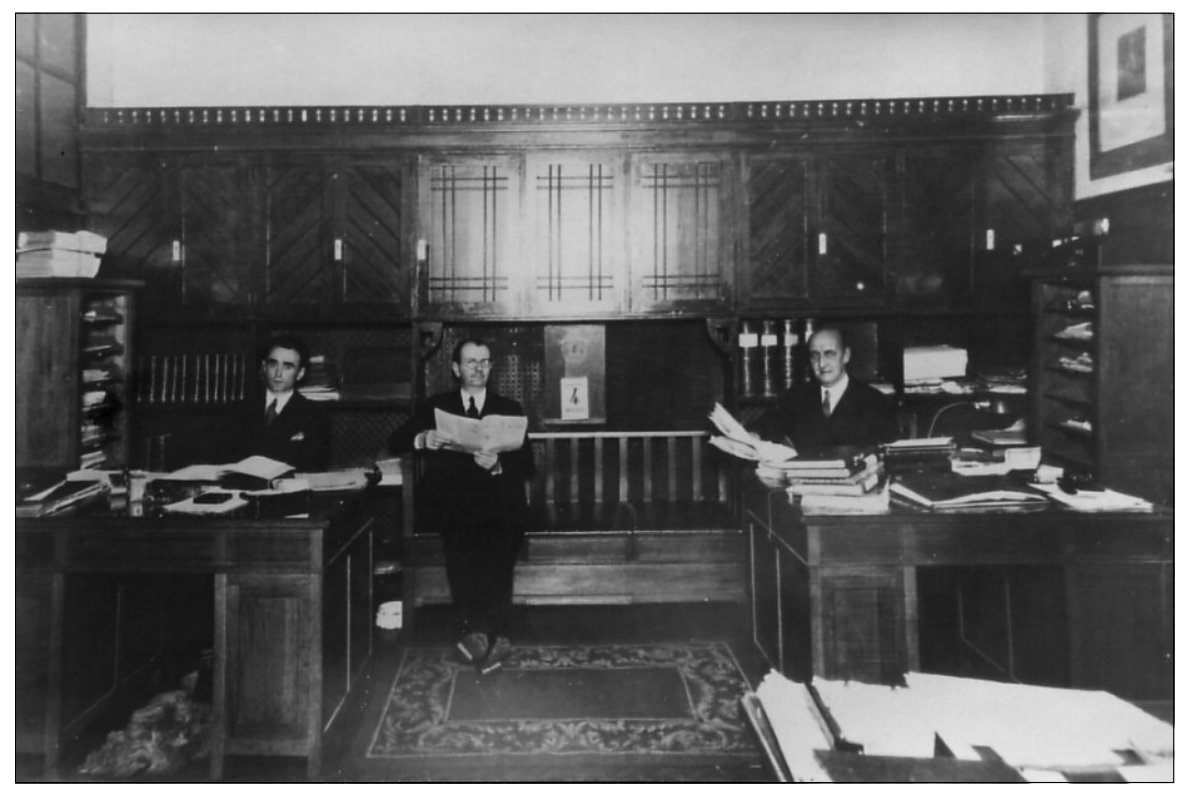

FIGURA 14. Delegación de Hacienda de Santander.

${ }^{42}$ AHN. FFCC. M.H.Leg. 6381-2. 
El encargado de dirigir estas reformas fue Miguel Durán, arquitecto director de las obras del Ministerio de Hacienda, quien durante varios años contratará a los mejores ebanistas y mueblistas activos en Madrid, en aquel momento ${ }^{43}$.

Todos los datos figuran en el "Expediente sobre aprobación del presupuesto adicional de decoración y reforma de los locales de acceso al despacho del Sr. Ministro, salones inmediatos al mismo y portería y alfombrado de los referidos locales y escalera". La cuenta rendida por Miguel Durán es de 30.526 ptas con cargo al remanente del suplemento de crédito concedido por R.D. de 26 de julio de 1929, que completaba al figurado en el capítulo adicional al presupuesto del mismo año, sección 11. Informado favorablemente el 29 agosto de 1930, Santa María realizaría las tapicerías y los empanelados de caoba, Vicente Zumel, las lámparas, recogiéndose además los presupuestos de vidrieras de Maumejean y de alfombras de Los Pontones.

Así, a los trabajos de Juan Martín, Vicente Mosteiro, Demetrio Martínez o Cándido Casas, quienes se encargan de la carpintería fija, empanelados y zócalos incluyendo los cubrerradiadores de caoba con costados de haya perforada del antedespacho del Ministro, de la sala de visitas de la Dirección General de lo Contencioso, esta con tableros "estilo antiguo", y todos los pasillos y despachos de este organismo, se añadirán los contratos de Algueró e Hijo en 1934 y 1936, para rehacer los zócalos de caoba y entarimado del despacho del Director General de lo Contencioso y realizar la chimenea de mármol para el despacho de la Dirección General del Tesoro $^{44}$. Es el momento en que se restauran los desperfectos de las pinturas de los techos del salón de actos y del despacho del Subsecretario. Junto a ellos aparecen los nombres de mueblistas de moda en Madrid entre 1929- 1930 como Manuel López (Muebles de lujo y ebanistería) quien emite una factura el 26 septiembre de 1930 por 25.457 ptas. por mobiliario suministrado y trabajos efectuados en las dependencias que se indican: portería mayor, despacho grande y pequeño del ministro, entelado y restauración de mobiliario del subsecretario y de su secretaría particular ${ }^{45}$. El detalle de la factura permite apreciar que se restaura una mesa de centro estilo imperio, un biombo de cuatro hojas, quizás el mismo que vimos comprar al inicio de este trabajo en 1904, y que se surte a la Subsecretaría de sillas de roble con asiento y respaldo de cuero. También queda registrada la empresa SantaMaría y Cia., que factura por las tapicerías del "salón azul y oro", del

\footnotetext{
43 AHN. FF.CC. M.H. Leg. 6468-1 año 1928.

${ }^{44}$ AHN. FF.CC. M.H. Leg. 6469-2 y 6470-1 años 1933-36.

${ }^{45}$ Ibidem Leg. 6469-1 (1929-30).
} 
antedespacho del Ministro, puertas de caoba y un balcón de caoba del mismo lugar. La cerrajería se encargó toda a Terán y Aguilar ${ }^{46}$.
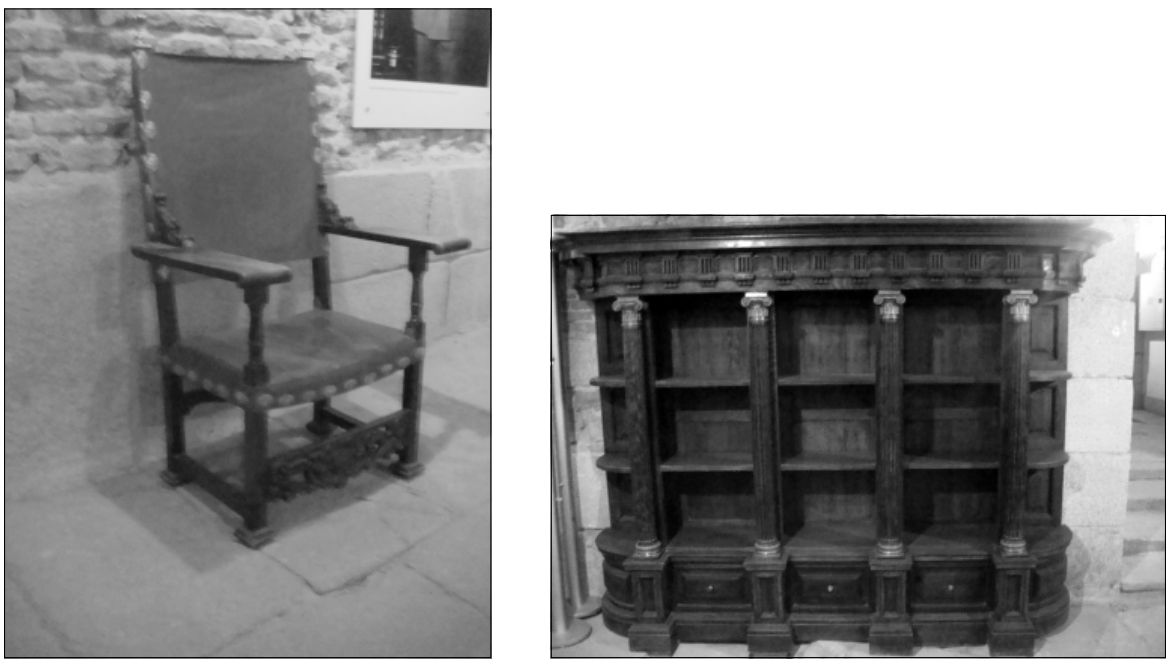

FIgURAS 15 y 16. Muebles conservados. Ministerio de Hacienda.

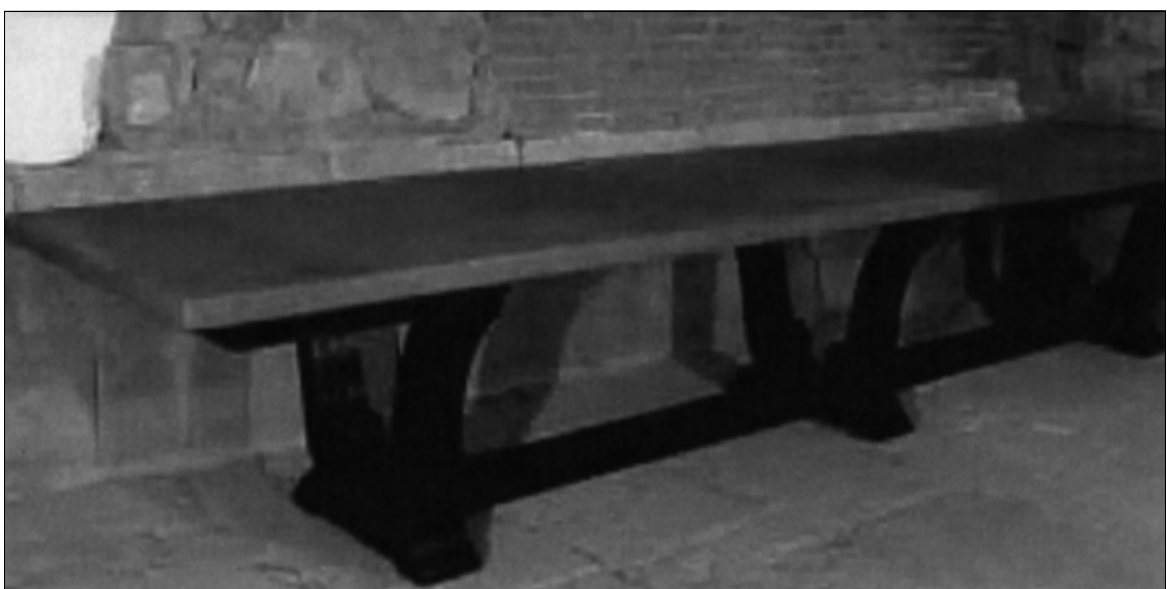

Figura 17. La "Mesa de Miaja". Ministerio de Hacienda.

Aparte de unos pocos arreglos realizados por Algueró e hijos entre los años $1931-36^{47}$, no se conserva más documentación hasta muchos años después. Del periodo que estudiamos nos quedan tres elementos conservados

${ }^{46}$ Gran Premio Exposición Internacional del Mueble de París. 1929.

${ }^{47}$ AHN. FF.CC. M.H. Leg 6470. 
en la exposición que se hizo sobre el asedio del edificio (Figs. 15, 16 y 17): Un par de sillones de cuero de tipo español que podrían ser cualquiera de los referidos en las cuentas y que aparecen documentados fotográficamente en algunos registros de actos, una librería de aspecto y recuerdo escurialense, realizada en madera de roble con columnas con capiteles corintios, cornisa con casetones etc., ante la que aparece el general Miaja en su foto oficial, y la mesa usada por el Estado Mayor de la Defensa conocida como "la mesa de Miaja”, que aparece repetidamente en las crónicas gráficas conservadas ${ }^{48}$. En los salones de representación se conserva un valioso mobiliario, así como la documentación pertinente que permite el estudio de la actividad de otras empresas en el periodo comprendido entre 1940 y 1980, pero que queda fuera del espacio temporal tratado en este estudio.

\section{ANEXO}

Casas Comerciales y Ebanistas en España en el periodo estudiado (ordenados cronológicamente)

\section{Primera época 1900-1905. Madrid}

VIUda De Alonso. Ebanistería y Tapicería. Calle del Prado nº 15.Frente a la de León. I Se construyen muebles De Todos estilos y épocas. Especialidad en sillas de cuero / Decorado de Habitaciones.

Mariano Abollo. Cardenal Cisneros 66. Madrid. "Proveedor de la Real Casa". "se construye toda clase de muebles de lujo, especialidad en cortinajes y decorado de habitaciones".

MANUEL SILLO.

JUAN HERRERA. Fuencarral, 10 principal. Se construyen para todos los gustos. Despachos, comedores, alcobas "Cortinajes, sillerias, gabinetes, armarios, chineros, aparadores, espejos"

Benjamín Roig. Se construyen para todos los gustos. Despachos, comedores, alcobas "Cortinajes, sillerias, gabinetes, armarios, chineros, aparadores, espejos".

Segunda época. 1924-1930. Toda España

Miguel Mavit. Plaza del Carmen 27. Granada. Muebles de estilo clásicos y modernos. Restauración de cuadros y muebles.

Ubaldo ABAD CARRETERo del Bazar "El León". Bazar y escritorio, calle Tiendas 6. Almería. Almacenes Rostrico 2-4 y 7. Talleres Humilladero 5. Muebles, loza y cristal. Batería

\footnotetext{
${ }^{48}$ Tipo conocido como "mesa de refectorio" con tablero de $3 \mathrm{~m}$ de largo, sobre patas en forma de ménsulas, utilizada por varios servicios del Ministerio y recuperada para la exposición permanente.
} 
de cocina y aluminio. Artículos para regalos. FÁBRICA DE MUEBLES. Palma de bonor y medalla de Oro en la Exposición Internacional de París.

ROGELIO FERRER. Casa especializada en instalaciones para bancos, ayuntamientos y casinos. c/ Real 9. Almería.

Manuel C. Varela (Lugo) Talleres de Ebanistería y Tapicería, San Pedro 5. Se construyen oratorios, retablos y confesonarios, pulpitos y atriles./ Géneros de primera. Especialidad con lavabos de alta novedad.

ANTONIO GONZÁLEZ DEL REY. Salamanca.

BADILlo. Sucesor P. Arenas. Alfonso XII 19 Sevilla.

Dionisio NAvajas. Fábrica de muebles. Exportación a provincias; especialidad en sillas y camas. Soliciten catálogos y presupuestos. Talleres Rua Vieja n. 05 y Marqués de San Nicolás 106 Logroño.

Víctor Gómez. Nuncio Viejo19. Toledo, inscrito en la Contribución industrial con el $n .^{\circ} 187$.

ReDONDO HeRMANOS. Ebanistería y tapicería c/ San Martín 48. San Sebastián.

Hijos De H. Hervada. Ferretería, Quincallería, Maquinaria agricola. Muebles. Piedras francesas para molinos. Representantes de varias compañias de vapores. La Coruna.

Gregorio de Frutos. Ebanista, Calle de Colón n. 9 Segovia.

Florencio ArCos. "LA CONSTRUCTORA". Fábrica de Muebles y Somieres. Calle Linares 10 Ceuta.

Almacenes "La COMPetidora". Antonio Mena López en calle Primo de Rivera 67 Ceuta.

Casa Munné. Grandes Almacenes. Barcelona. Muebles Munné. Ronda de San Antonio 80 $y$ 82. Figura en el Registro de contribución con Tarifa 1ª , clase 3, epígrafe 4, n.․․ 364 como vendedor de muebles finos.

ANTONIO GONZÁLES DEL REY. Salamanca.

Eladio Campe Amaya. "Casa Campe". Cádiz.

Adolfo Ramírez. Conde Duque 4. Madrid.

GonzÁlez Calvo. Antes "casa Sessé". Juan Bravo 36. Segovia.

Julıo Íñiguez. Calle del General Sanz Pastor n.․ 4. Ebanistería y almacén de muebles.

Pedro Armengol MarTí. Rambla Fernando 16. Lérida.

Manuel Restegui. Muebles, bronces artísticos y decoración. Alameda de Oviedo 47. Santander.

ANTONIO BonilLa. Gran fábrica de muebles de todas clases. Vitoria.

Tercera época. 1927-1934. Madrid

Algueró E HIJO. Industrias Artísticas. Oficinas Maldonado 5 - talleres $M^{\underline{a}}$ de Molina 15almacenes Chamartín de la Rosa. / escultura / bronces / ebanistería / arte / decoración / mármoles.

CÁNDIDO Casas. Antonio López 4.

Ángel Canosa. Travesía de Pozas 4 (frente a la Universidad). Carpintería, persianas, embalajes.

CRistalería Vic. Los Madrazo 24. Lunas biseladas, con y sin escudo. Portería.

Julián Galvín. Ebanistería y carpintería. Ayala n. 19. tel. 53414 / Construye toda clase de obra de carpintería / Construcción y restauración de toda clase de muebles.

JUAN GARCÍA, DORADOR Y DECORADOR. Se doran altares y muebles. se restauran cuadros antiguos. especialidad en flores pintadas al óleo". 
LissarRaga \& sobrinos. Muebles artísticos decorados. Carrera de San Jerónimo 39/ Talleres Conde de Barajas 2 / Directores propietarios J. y J. VILLALBA.

MANuel López. Muebles de lujo y tapicería (membrete con angelitos).

Los Pontones. Fábrica de alfombras y tapices. Paseo de las Acacias n. 2. Oficinas Serrano 22.

Juan Martín. Ponzano 43. Tel. 80180. "Talleres mecánicos de carpintería y ebanistería. / Especialidad en mobiliario para escuelas, universidad y academias / Construcción de toda clase de obras de carpintería, ebanistería y tapicería".

Demetrio MarTínez. San Gregorio 27.

Vicente Mosteiro. Luisa Fernanda 10. Tel. 8885. "Se hacen toda clase de muebles. Se hace toda clase de obra de carpintería. Especialidad en tiendas".

F. Nicoli. Talleres y Almacén de Mármol. Calle del Comercio n. 2 y Pórtico 28 central Alcalá 50. 1929.

MANUEL NúÑEZ. Carpintería. "Construcción y restauración de toda clase de obra de carpintería / muebles, persianas y entarimados / embalador a la francesa"

RÁmaga R. Rodríguez. Hnos. Clavel 2. "tapicerias, alfombras, decoración".

SANTA MARía. Talleres en San Martín de Vargas 3; Batalla del Salado 9 y Palos de Moguer 25.

S. Santa-María y Cía. Talleres: Agustín Durán no 33. Exposición Jovellanos 5. Tel. 11258. "Muebles y Decoración. Dirección artística L.S. Santa-María. L.M.Feduchi Arquitecto".

SOCIEDAD MAUMejEAN. Hnos. de Vidriería artística S.A. Casa fundada en 1860. Vidrieras de arte, Mosaicos Venecianos/Madrid Paseo de la Castellana 76/ San Sebastián. Pedro de Egaña 8 / Paris, 6 rue Bezou.t XVI arrondi / Hendaya. Puente de Santiago.

Terán y Aguilar S.A. Bronces de Arte. Gran Premio Exposición Internacional del Mueble de Barcelona. Zurbano 65. Tel. 33903. Apdo. 252. Realiza manillas, placas, manivelas, cremotas.

Vicente Zumel. "Talleres de Arte Español. Exposición y venta Gran Vía 16. Talleres Doctor Esquerdo 6. Madrid. Fabricante de arañas de bronce para alumbrado eléctrico, Hierros artísticos y repujados. Especialidad en lámparas plateadas Renacimiento español".

\section{BIBLIOGRAFÍA CITADA}

Aguiló-Alonso, M.-P. 2005. "Mobiliario y decoración en la historia del CBA", en El Círculo de Bellas Artes de Madrid. Ciento veinticinco años de historia 1880-2005: 49-64. Madrid: Círculo de Bellas Artes.

Barea, A. 2007. La forja de un rebelde. (1를 edición inglesa 1941-44). Madrid: Alianza.

Buades Torrent, J. 1988. El edificio del Ministerio de Hacienda y su tesoro artístico. Madrid: Ministerio de Economía y Hacienda (1 $1^{\underline{a}}$ ed. 1982).

Despachos. 1953. Monografías "Arte y Hogar". Madrid: Editorial Cigüeña.

Díez De Monleón, C. 1986. Arquitectura y clases sociales en el Madrid del siglo XIX. Madrid: Siglo XXI Editores.

El Cuerpo de Abogados del Estado 11 marzo 1881-10 marzo 1931. Madrid: Imprenta de Jesús Gómez.

Las Delegaciones De Hacienda. Su historia (1881-1981). 1981. Madrid: Instituto de Estudios Fiscales.

La Hacienda Pública en la época de los Borbones. 1980. Catálogo exposición. Madrid. 
Ministerio de Hacienda. Crónica gráfica (1852-2005). 2005. Madrid: Ministerio de Economía y Hacienda.

Rodríguez Bernis, S. 2006. Diccionario de Mobiliario. Madrid: Ministerio de Cultura.

Tesoros de la Real Casa de la Aduana. Ministerio de Economía y Hacienda. PDF.

VV.AA. 2005. Visita guiada a la Real Casa de la Aduana. Ministerio de Economía y Hacienda.

Fecha de recepción: 11 de diciembre de 2007

Fecha de aceptación: 11 de diciembre de 2008 